pubs.acs.org/joc

\title{
Two-Step Synthesis of Aza- and Diazaindoles from Chloroamino- $N$-heterocycles Using Ethoxyvinylborolane
}

\author{
Daniel K. Whelligan, Douglas W. Thomson, Dawn Taylor, and Swen Hoelder* \\ Cancer Research UK Centre for Cancer Therapeutics, The Institute of Cancer Research, Haddow \\ Laboratories, 15 Cotswold Road, Sutton, Surrey SM2 5NG, U.K.
}

swen.hoelder@icr.ac.uk

Received October 7, 2009

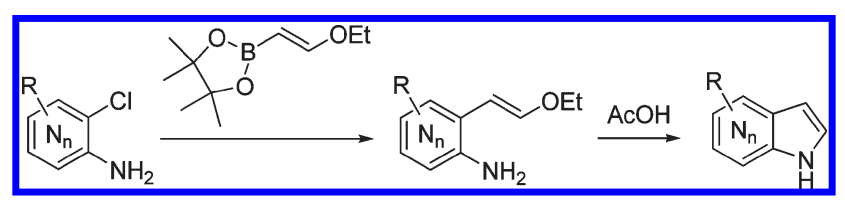

An efficient two-step route to a broad range of aza- and diazaindoles was established, starting from chloroamino- $N$-heterocycles, without the need for protecting groups. The method involves an optimized Suzuki-Miyaura coupling with (2-ethoxyvinyl)borolane followed by acetic acid-catalyzed cyclization.

\section{Introduction}

Azaindoles form the core of many biologically active compounds, such as kinase inhibitors, and are therefore often employed in drug discovery programs. ${ }^{1,2}$ The synthesis of the azaindole scaffold can prove challenging, and several of the classical indole formation methods, such as the Fischer

(1) For selected recent examples of kinase inhibitors, see: (a) Dyke, H. J.; Price, S.; Williams, K. Patent Application WO2008157179, 2008. (b) Graczyk, P. P.; Dimopoulos, P.; Farthing, C. N.; Bhatia, G. S.; Khan, A. Patent Application WO2008095943, 2008. (c) Graczyk, P. P.; Dimopoulos, P.; Khan, A.; Bhatia, G. S.; Farthing, C. N. Patent Application WO2008095944, 2008. (d) Tsai, J.; Lee, J. T.; Wang, W.; Zhang, J.; Cho, H.; Mamo, S.; Bremer, R.; Gillette, S.; Kong, J.; Haass, N. K.; Sproesser, K.; Li, L.; Smalley, K. S. M.; Fong, D.; Zhu, Y.-L.; Marimuthu, A.; Nguyen, H.; Lam, B.; Liu, J.; Cheung, I.; Rice, J.; Suzuki, Y.; Luu, C.; Settachatgul, C.; Shellooe, R.; Cantwell, J.; Kim, S.-H.; Schlessinger, J.; Zhang, K. Y. J.; West, B. L.; Powell, B.; Habets, G.; Zhang, C.; Ibrahim, P. N.; Hirth, P.; Artis, D. R.; Herlyn, M.; Bollag, G. Proc. Natl. Acad. Sci. U.S.A. 2008, 105, 3041. (e) Lefoix, M.; Coudert, G.; Routier, S.; Pfeiffer, B.; Caignard, D.-H.; Hickman, J.; Pierre, A.; Golsteyn, R. M.; Leonce, S.; Bossard, C.; Merour, J.-Y. Bioorg. Med. Chem. 2008, 16, 5303. (f) Echalier, A.; Bettayeb, K.; Ferandin, Y.; Lozach, O.; Clelment, M.; Valette, A.; Liger, F.; Marquet, B.; Morris, J. C.; Endicott, J. A.; Joseph, B.; Meijer, L. J. Med. Chem. 2008, 51, 737.

(2) For recent examples of nonkinase inhibitors, see: (a) Stoit, A.; Coolen, H. K. A. C.; Van Der Neut, M. A. W.; Kruse, C. G. Patent Application WO 2008003736, 2008. (b) Lu, R.-J.; Tucker, J. A.; Zinevitch, T.; Kirichenko, O.; Konoplev, V.; Kuznetsova, S.; Sviridov, S.; Pickens, J.; Tandel, S.; Brahmachary, E.; Yang, Y.; Wang, J.; Freel, S.; Fisher, S.; Sullivan, A.; Zhou, J.; StanfieldOakley, S.; Greenberg, M.; Bolognesi, D.; Bray, B.; Koszalka, B.; Jeffs, P.; Khasanov, A.; Ma, Y.-A.; Jeffries, C.; Liu, C.; Proskurina, T.; Zhu, T.; Chucholowski, A.; Li, R.; Sexton, C. J. Med. Chem. 2007, 50, 6535.

(3) For reviews on azaindoles, see: (a) Popowycz, F.; Routier, S.; Joseph, B.; Merour, J.-Y. Tetrahedron 2007, 63, 1031. (b) Popowycz, F.; Merour, J.-Y.; Joseph, B. Tetrahedron 2007, 63, 8689. (c) Song, J. J.; Reeves, J. T.; Gallou, F.; Tan, Z.; Yee, N. K.; Senanayake, C. H. Chem. Soc. Rev. 2007, 36, 1120. (d) Merour, J.-Y.; Joseph, B. Curr. Org. Chem. 2001, 5, 471. (e) Le Hyaric, M.; Vieira de Almeida, M.; Nora de Souza, M. V. Quim. Nova 2002, 25,1165 . indole synthesis, give poor results or require the use of protecting groups. ${ }^{3}$ We wished to develop a robust method of synthesizing a variety of aza- and diazaindoles from readily available, inexpensive starting materials, in particular, chloroarenes, such as $\mathbf{1}$ (Scheme 1), which would be useful for preparing libraries for fragment-based approaches to drug discovery. ${ }^{4}$ We were particularly interested in access to azaindoles without substitution in the 2-position since this is often preferred in kinase drug discovery programs. ${ }^{5} \mathrm{Sev}-$ eral literature methods start from haloaminopyridines and install the 5-membered ring through a $\mathrm{Pd}$-catalyzed $\mathrm{C}-\mathrm{C}$ coupling reaction (Sonogashira, Stille, Suzuki-Miyaura, or Heck) and subsequent cyclization. However, few, if any, such existing methods have been shown to be applicable to the synthesis of all azaindole regioisomers, especially 5-azaindole. ${ }^{3,6-9}$ Furthermore, most of the examples described start from the corresponding bromides or iodides or begin from the halonitroarene. ${ }^{10,11}$ We wanted to use

(4) Hajduk, P. J.; Greer, J. Nature Rev. Drug Discov. 2007, 6, 211.

(5) Numerous examples exist in the literature. In this one, substituents in the 2-position decrease the activity of the azaindole inhibitor: Tang, J.; Hamajima, T.; Nakano, M.; Sato, H.; Dickerson, S. H.; Lackey, K. E. Bioorg. Med. Chem. Lett. 2008, 18, 4610.

(6) Xu, Z.; Hu, W.; Zhang, F.; Li, Q.; Lü, Z.; Zhang, L.; Jia, Y. Synthesis 2008, 24, 3981 .

(7) (a) Majumdar, K. C.; Mondal, S. Tetrahedron Lett. 2007, 48, 6951. (b) Majumdar, K. C.; Samanta, S.; Chattopadhyay, B. Tetrahedron Lett. 2008, $49,7213$.

(8) Jeanty, M.; Suzenet, F.; Guillaumet, G. J. Org. Chem. 2008, 73, 7390.

(9) Schirock, H. J. Org. Chem. 2006, 71, 5538.

(10) Sun, L.-P.; Wang, J.-X. Synth. Commun. 2007, 37, 2187.

(11) Jensen, T.; Pedersen, H.; Bang-Andersen, B.; Madsen, R.; Jørgensen, M. Angew. Chem., Int. Ed. 2008, 47, 888 . 
SCHEME 1. Desired Synthetic Conversion

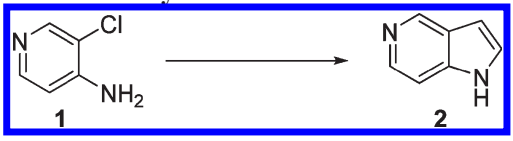

SCHEME 2. Synthesis of Ethoxyvinylborolane 5

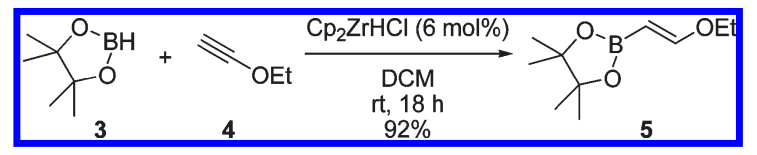

chloroarenes as they are often cheaper and more readily commercially available than bromo- or iodoarenes, although they are generally known to be more difficult coupling partners in Pd-catalyzed cross-coupling reactions. ${ }^{12}$ Of all the chloroaminopyridines available, 4-amino-3-chloropyridine 1 (Scheme 1) was considered the most difficult regioisomer to couple in $\mathrm{Pd}$-catalyzed reactions for two reasons: (i) the chlorine atom on the ring is meta to the pyridine nitrogen atom and thus is less activated and (ii) the position of the amino group para to the pyridine nitrogen makes the whole molecule rather basic $\left(\mathrm{p} K_{\mathrm{a}}=7.2\right)$ and strongly coordinating. ${ }^{13,14}$ To the best of our knowledge, use of this unprotected substrate in a $\mathrm{Pd}$-catalyzed coupling reaction has never been reported.

\section{Results and Discussion}

Our initial attempts at this transformation included Sonogashira coupling of trimethylsilylacetylene (it was presumed the TMS group could be removed from the 2-position at a later stage) followed by base-mediated cyclization, described by McLaughlin, ${ }^{15}$ but this left the starting material $\mathbf{1}$ intact. Also tested was the use of an ethoxyvinyltin reagent in a Stille coupling (prior to acid-mediated cyclization) ${ }^{16}$ but, with substrate $\mathbf{1}$, this proceeded in only $7 \%$ LC yield. The low yield and the toxic nature of the tin reagent prompted us to use the respective borolane, a catechol version of which has been described for the synthesis of 7-azaindoles from 2-amino-3-iodopyridine. ${ }^{17,18}$

Borolane 5 is commercially available ${ }^{19}$ or can be synthesized in one step (Scheme 2 ) by $\mathrm{Cp}_{2} \mathrm{ZrHCl}$-catalyzed hydroboration ${ }^{20}$ of ethoxyethyne $\mathbf{4}$. Borolane 5 could be obtained in $92 \%$ yield through use of an optimized purification procedure involving filtration through a pad of neutral alumina topped with a layer of Celite and elution with DCM.

(12) Littke, A. F.; Fu, G. C. Angew. Chem., Int. Ed. 2002, 41, 4176

(13) Itoh, T.; Mase, T. Tetrahedron Lett. 2005, 46, 3573.

(14) Rasala, D. Bull. Soc. Chim. Fr. 1992, 5, 509.

(15) McLaughlin, M.; Palucki, M.; Davies, I. W. Org. Lett. 2006, 8, 3307.

(16) (a) Sakamoto, T.; Satoh, C.; Kondo, Y.; Yamanaka, H. Heterocycles 1992, 34, 2379 and references cited therein. (b) Cheung, M.; Harris, P. A.; Lackey, K. E. Tetrahedron Lett. 2001, 42, 999. (c) Hong, J.; Gray, N. S.; Schultz, P. Patent Application WO2005/107760, 2005. (d) Moriarty, K. J.; Koblish, H. K.; Garrabrant,

T.; Maisuria, J.; Khalil, E.; Ali, F.; Petrounia, I. P.; Crysler, C. S.; Maroney, A. C.; Johnson, D. L.; Galemmo, R. A., Jr. Bioorg. Med. Chem. Lett. 2006, 16, 5778.

(e) Choi, H.-S.; Wang, Z.; Richmond, W.; He, X.; Yang, K.; Jiang, T.; Sim, T.;

Karanewsky, D.; Gu, X-j.; Zhou, V.; Liu, Y.; Ohmori, O.; Caldwell, J.; Gray, N.; He,

Y. Bioorg. Med. Chem. Lett. 2006, 16, 2173.

(17) Satoh, M.; Miyaura, N.; Suzuki, A. Synthesis 1987, 373.

(18) Kumar, V.; Dority, J. A.; Bacon, E. R.; Singh, B.; Lesher, G. Y. J. Org. Chem. 1992, 57, 6995.

(19) (Z-isomer): Apollo Scientific Ltd. (http://www.apolloscientific.co. uk) and Synthonix Corporation (http://www.synthonix.com). 102.

(20) Hoffmann, R. W.; Krüger, J.; Brückner, D. New.J. Chem. 2001, 25,
TABLE 1. Development of Coupling Conditions

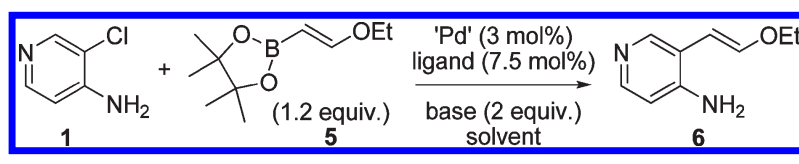

\begin{tabular}{|c|c|c|c|c|c|}
\hline entry & base & solvent & catalyst & $\underset{/{ }^{\circ} \mathrm{C}}{\text { temp }}$ & $\begin{array}{r}\text { yield } \\
(\%)\end{array}$ \\
\hline 1 & $\mathrm{Na}_{2} \mathrm{CO}_{3}$ & $\begin{array}{l}\mathrm{DME} / \mathrm{H}_{2} \mathrm{O} \\
(9: 1)\end{array}$ & $\mathrm{Pd}\left(\mathrm{PPh}_{3}\right)_{4}$ & 85 & \\
\hline 2 & $\mathrm{Na}_{2} \mathrm{CO}_{3}$ & $\begin{array}{l}\mathrm{DME} / \mathrm{H}_{2} \mathrm{O} \\
(7: 3)\end{array}$ & $\mathrm{PdCl}_{2}(\mathrm{dppf})^{b}$ & $140^{c}$ & \\
\hline 3 & $\mathrm{~K}_{3} \mathrm{PO}_{4}$ & THF & $\mathrm{Pd}(\mathrm{OAc})_{2} / \mathrm{SPhos}$ & 66 & \\
\hline 4 & $\mathrm{~K}_{3} \mathrm{PO}_{4}$ & dioxane & $\mathrm{Pd}(\mathrm{OAc})_{2} / \mathrm{SPhos}$ & 101 & \\
\hline 5 & $\mathrm{~K}_{3} \mathrm{PO}_{4}$ & dioxane & $\mathrm{Pd}(\mathrm{OAc})_{2} /$ SPhos & $130^{c}$ & $<$ \\
\hline 6 & $\begin{array}{l}\mathrm{K}_{3} \mathrm{PO}_{4} \\
\text { or } \mathrm{Cs}_{2} \mathrm{CO}_{3}\end{array}$ & dioxane & Various - see text & 101 & \\
\hline 7 & $\mathrm{~K}_{3} \mathrm{PO}_{4}$ & dioxane & $\mathrm{Pd}(\mathrm{OAc})_{2} / \mathrm{D}-\mathrm{t}-\mathrm{BPF}^{b}$ & 101 & $<$ \\
\hline 8 & $\mathrm{~K}_{3} \mathrm{PO}_{4}$ & $\mathrm{MeCN}$ & $\mathrm{Pd}(\mathrm{OAc})_{2} / \mathrm{SPhos}$ & 81 & 3 \\
\hline 9 & $\mathrm{~K}_{3} \mathrm{PO}_{4}$ & $\mathrm{MeCN} / \mathrm{H}_{2} \mathrm{O}$ & $\mathrm{Pd}(\mathrm{OAc})_{2} / \mathrm{SPhos}$ & 75 & \\
\hline
\end{tabular}

$(3: 2)$

${ }^{a}$ After stirring overnight (unless stated otherwise), LC yield referenced to anthracene internal standard. ${ }^{b} 3 \mathrm{~mol} \%$ of ligand. ${ }^{c}$ Microwave for $10 \mathrm{~min}$ (entry 2 ) or $1 \mathrm{~h}$ (entry 5$).{ }^{d}$ After $72 \mathrm{~h}$.

With this reagent in hand, optimization studies on its SuzukiMiyaura coupling with 4-amino-3-chloropyridine 1 were carried out (Table 1). Commonly used Suzuki-Miyaura conditions failed (entry 1) or gave up to $5 \%$ product when forced at high temperature under microwave conditions (entry 2). Buchwald et al. have shown the use of a catalyst generated in situ from 2-dicyclohexylphosphino-2',6'-dimethoxybiphenyl (SPhos) and $\mathrm{Pd}(\mathrm{OAc})_{2}$ to be particularly good for Suzuki-Miyaura-type cross-couplings with aryl chlorides. ${ }^{21}$ Unfortunately, with substrate $\mathbf{1}$ in refluxing THF no product was formed (entry 3). However, repetition at higher temperature in dioxane (entry 4) did provide a very small amount of the product. The addition of extra $\mathrm{Pd}(\mathrm{OAc})_{2} / \mathrm{SPhos}$ and/or borolane 5 did not push the reaction any further. Reaction at an even higher temperature using a sealed tube under microwave conditions gave the same result (entry 5). Furthermore, neither increasing the catalyst loading to $20 \mathrm{~mol} \%$ nor using $\mathrm{Pd}(\mathrm{dba})_{2}$ as a source of $\mathrm{Pd}(0)$ gave any significant increase in yield.

Alternative regioisomers 3-chloro-2-aminopyridine and 2-chloro-3-aminopyridine and the more reactive 4-amino3 -bromopyridine also did not couple with borolane 5 beyond $3 \%$ yield under these conditions.

To eliminate the possibility that ethoxyvinylborolane $\mathbf{5}$ cannot couple or decomposes under these conditions, it was tested in a reaction with 4-chloroaniline 7, previously shown to couple efficiently with a range of borolanes. ${ }^{21}$ This reaction was successful, giving 52\% product (entry 1, Table 2). Conversely, 2,4-difluorophenylboronic acid reacted minimally with 4-amino-3-chloropyridine $\mathbf{1}$. Since 2,4-difluorophenylboronic acid has been shown to readily undergo Suzuki-Miyaura couplings, it was thought that the aminopyridine compounds (starting material, an intermediate or the small amount of product produced) were poisoning the catalyst by complexing palladium. ${ }^{13}$ This has been noted previously in similar systems by Lautens ${ }^{22}$ and was

(21) Barder, T. E.; Walker, S. D.; Martinelli, J. R.; Buchwald, S. L. J.Am. Chem. Soc. 2005, 127, 4685.

(22) Fang, Y.-Q.; Yuen, J.; Lautens, M. J. Org. Chem. 2007, 72, 5152. 
TABLE 2. Catalyst Poisoning Tests

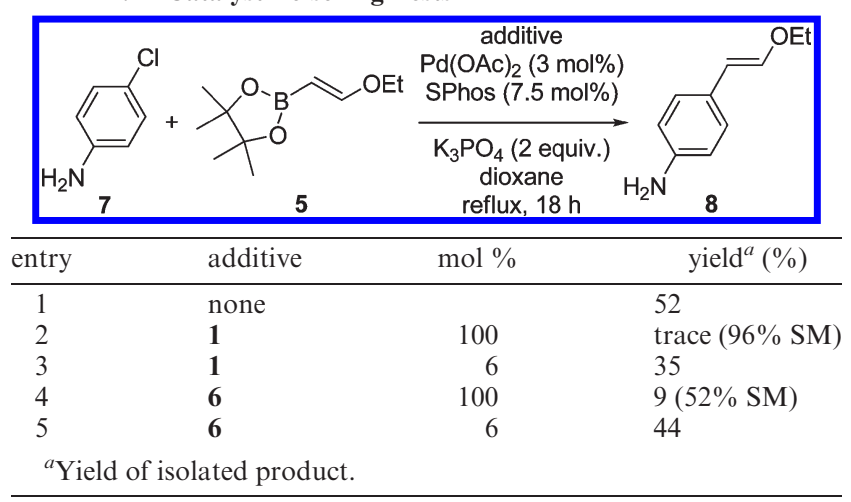

TABLE 3. Optimization of the Coupling Conditions

\begin{tabular}{|c|c|c|c|c|c|}
\hline 1 & $\mathrm{NH}_{2}{ }^{+}$ & Ó & $\begin{array}{r}\mathrm{Pd}(\mathrm{OA} \\
\\
\text { base } \\
\mathrm{MeCl} \\
\text { ref }\end{array}$ & $\begin{array}{l}3 \mathrm{~mol} \%) \\
\mathrm{es} \\
\begin{array}{l}\text { equiv.) } \\
(3: 2) \\
18 \mathrm{~h}\end{array}\end{array}$ & ${ }_{6}{ }_{\mathrm{NH}_{2}}$ \\
\hline entry & base & borolane 5 & equiv) & ratio $\mathrm{P}: \mathrm{Pd}$ & $\operatorname{yield}^{a}(\%)$ \\
\hline 1 & $\mathrm{~K}_{3} \mathrm{PO}_{4}$ & 1.2 & & 2.5 & 31 \\
\hline 2 & $\mathrm{Na}_{2} \mathrm{CO}_{3}$ & 1.2 & & 2.5 & 24 \\
\hline 3 & $\mathrm{~K}_{2} \mathrm{CO}_{3}$ & 1.2 & & 2.5 & 26 \\
\hline 4 & $\mathrm{Cs}_{2} \mathrm{CO}_{3}$ & 1.2 & & 2.5 & 31 \\
\hline 5 & $\mathrm{~K}_{3} \mathrm{PO}_{4}$ & 1.2 & & 2.0 & 24 \\
\hline 6 & $\mathrm{~K}_{3} \mathrm{PO}_{4}$ & 1.2 & & 3.0 & 28 \\
\hline 7 & $\mathrm{~K}_{3} \mathrm{PO}_{4}$ & 1.5 & & 2.5 & 40 \\
\hline 8 & $\mathrm{~K}_{3} \mathrm{PO}_{4}$ & 2.0 & & 2.5 & $45(44)$ \\
\hline 9 & $\mathrm{~K}_{3} \mathrm{PO}_{4}$ & 2.5 & & 2.5 & 39 \\
\hline
\end{tabular}

${ }^{a}$ After stirring overnight, LC yield referenced to anthracene internal standard. Yield of isolated product in parentheses.

supported by further experiments shown in Table 2: addition of 1 equiv of 4-amino-3-chloropyridine 1 to the normally successful reaction with chloroaniline 7 effectively halted the reaction (entry 2). Furthermore, only 6 mol \% of 1 reduced the yield from $52 \%$ to $35 \%$. The similarly basic ethoxyvinylaminopyridine product 6 also inhibited the reaction, though to a slightly lesser degree (entries 3 and 4).

We hypothesized that an alternative ligand might prevent complexation of palladium by the aminopyridines so a screening of several ligands was performed. However, under the same conditions, $\mathrm{Pd}\left(\mathrm{PPh}_{3}\right)_{4}, \mathrm{PdCl}_{2}(\mathrm{dppf}), \mathrm{Pd}(\mathrm{OAc})_{2} /(\text { adamantyl })_{2}$ $\mathrm{BuP},{ }^{23} \mathrm{Pd}(\mathrm{OAc})_{2} / \mathrm{XPhos}^{24}$ and $\mathrm{Pd}(\mathrm{OAc})_{2} / 2$-(dimethylamino)$2^{\prime}$-dicyclohexylphosphinobiphenyl ${ }^{25}$ in combination with either $\mathrm{K}_{3} \mathrm{PO}_{4}$ or $\mathrm{Cs}_{2} \mathrm{CO}_{3}$ as base (entry 6, Table 1) gave no detectable product by LC. Itoh has shown that, under the same conditions, bis(di-tert-butylphosphino)ferrocene (D-t-BPF) is a particularly good ligand for the Suzuki-Miyaura coupling of $\mathrm{NH}_{2}-$ substituted heterocycles. ${ }^{13}$ Again, with our substrate, only a trace amount of product was formed (entry 7, Table 1). Further research with SPhos showed that the use of toluene at reflux resulted in no reaction but DMA at $120{ }^{\circ} \mathrm{C}$ promoted a fast reaction which stopped at $10 \%$ product after $30 \mathrm{~min}$. A significant improvement was achieved with $\mathrm{MeCN}$ which gave

(23) Pews-Davtyan, A.; Tillack, A.; Ortinau, S.; Rolfs, A.; Beller, M. Org. Biomol. Chem. 2008, 6, 992.

(24) Billingsley, K.; Buchwald, S. L. J. Am. Chem. Soc. 2007, 129, 3358.

(25) Old, D. W.; Wolfe, J. P.; Buchwald, S. L. J. Am. Chem. Soc. 1998, 120,9722 . a yield of $34 \%$ but only after $72 \mathrm{~h}$ at reflux (entry 8 , Table 1 ). Finally, use of a $3: 2$ mixture of $\mathrm{MeCN} / \mathrm{H}_{2} \mathrm{O}$, as used by Buchwald et al., gave $31 \%$ yield overnight (entry 9 , Table 1 ). ${ }^{26}$

Further optimization, shown in Table 3, revealed that $\mathrm{K}_{3} \mathrm{PO}_{4}$ was the most effective base of those tested (entries $1-4$ ), a ligand to Pd ratio (P:Pd) of 2.5:1 was best (entries 4-6) and the use of 2.0 equiv of borolane 5 was optimum (entries 7-9). SPhos $/ \mathrm{Pd}(\mathrm{OAc})_{2}$ is still the catalyst of choice in this solvent mixture as tests with $\mathrm{Pd}\left(\mathrm{PPh}_{3}\right)_{4}, \mathrm{PdCl}_{2}(\mathrm{dppf})$, and $\mathrm{Pd}(\mathrm{OAc})_{2} / \mathrm{D}-t-\mathrm{BPF}$ gave no product or $\sim 5 \%$ (LC yield) with the latter.

Upon finding successful coupling conditions (entry 8, Table 3, hereafter named method A), the scope of the reaction was assessed with a range of substrates (Table 4) including all pyridine regioisomers. All substrates reacted in good to high yields except for 2,4-dichloro-5-aminopyrimidine (entry 10) and 2-chloroaniline (entry 12) which produced a range of unidentified decomposition products. Of the pyridines, the 4-amino-3-halopyridines gave the lowest yields (entries 2 and 5) which is attributed to their strong Lewis basicity and the unreactive position of the halide, as described above.

The Suzuki-Miyaura products $\mathbf{1 0}$ were all successfully cyclized to the desired azaindoles $\mathbf{1 1}$ in good to excellent yields using acetic acid.

It was thought that the change in solvent system to include water might allow the reaction to work because of the in situ generation of $\mathrm{KOH}$. Accordingly, $\mathrm{NaOH}$ was the base used by Suzuki to couple ethoxyvinylboranes with iodoanilines. ${ }^{17}$ We tested this hypothesis in three experiments on substrate $\mathbf{1}$ (entry 2, Table 4) by using $\mathrm{KOH}$ in $\mathrm{MeCN}$ (method B), dioxane (method $\mathrm{C}$ ), and the $\mathrm{MeCN} / \mathrm{H}_{2} \mathrm{O}$ mixture (method D). The reaction proceeded to an extent in all solvents, but $\mathrm{MeCN}$ gave the highest yield thus far with substrate $\mathbf{1}$. The yield could be further increased to $69 \%$ by doubling the amount of catalyst. Interestingly, use of $\mathrm{KOH}$ in the $\mathrm{MeCN} /$ $\mathrm{H}_{2} \mathrm{O}$ mixture gave a low yield of product. One possible explanation for these results is a requirement for a constantly small concentration of $\mathrm{KOH}$ which might arise through partial solubility (in $\mathrm{MeCN}$ or dioxane) or by existing in equilibrium with $\mathrm{K}_{3} \mathrm{PO}_{4}$ and water.

Interestingly, use of $\mathrm{KOH}$ in $\mathrm{MeCN}(\operatorname{method} \mathrm{B})$ with the more sensitive substrates 4-chloro-3-aminopyridine (entry 3), 3-bromo-4-aminopyridine (entry 5), and dichloroaminopyrimidine (entry 10) gave considerably lower yields, the latter giving a complex mixture of products. On the other hand, the yield of product formed from chloroaniline using these conditions was quantitative (method B, entry 12), a dramatic increase from that using the original conditions of method A.

Although the 3-position of azaindoles can be substituted readily by well-known halogenation and cross-coupling, ${ }^{27}$ it was still of interest to see if this substitution could be achieved using 1-substituted borolanes. Thus, $n$-butyl-substituted borolane 13 was synthesized as shown in Scheme 3. ${ }^{28}$

(26) Billingsley, K. L.; Anderson, K. W.; Buchwald, S. L. Angew. Chem. Int. Ed. 2006, 45, 3484

(27) (a) Gallou, F.; Reeves, J. T.; Tan, Z.; Song, J. J.; Yee, N. K.; Harcken, C.; Liu, P.; Thomson, D.; Senanayake, C. H. Synlett 2007, 2, 211. (b) Sakamoto, T.; Kondo, Y.; Sato, S.; Yamanaka, H. J. Chem. Soc. Perkin Trans. 1 1996, 5, 459. (c) Kelly, T. A.; McNeil, D. W.; Rose, J. M.; David, E.; Shih, C.-K.; Grob, P. M. J. Med. Chem. 1997, 40, 2430.

(28) Acetylene 12 was synthesized according to Pons, J.-M.; Kocieski, P. Tetrahedron Lett. 1989, 30,1833, but DMPU was substituted for highly toxic HMPA. 
TABLE 4. Coupling of Various Substrates Followed by Cyclization

(2)

${ }^{a}$ Solvent volume to make a $0.1 \mathrm{M}$ solution of substrate. ${ }^{b}$ Method A: $\mathrm{K}_{3} \mathrm{PO}_{4}, \mathrm{MeCN} / \mathrm{H}_{2} \mathrm{O}(3: 2)$. Method B: $\mathrm{KOH}, \mathrm{MeCN}$. Method C: $\mathrm{KOH}$, dioxane. Method D: $\mathrm{KOH}, \mathrm{MeCN} / \mathrm{H}_{2} \mathrm{O}(3: 2)^{c}$ Yield of isolated product. ${ }^{d} 6 \mathrm{~mol} \%$ of $\mathrm{Pd}(\mathrm{OAc})_{2}, 15 \mathrm{~mol} \%$ of SPhos.

Unfortunately, using method B, this compound did not couple at all with 4-amino-3-chloropyridine 1, leaving only starting material. To check that borolane $\mathbf{1 3}$ was indeed active, it was coupled with the simpler and more reactive iodoaniline 14. This reaction went in $74 \%$ yield (and the product was readily cyclized to the 3 -substituted indole $\mathbf{1 6}$ ). These results might indicate that the 1-substituted borolane,
SCHEME 3. Synthesis and Reaction of Bu-Substituted Borolane 13

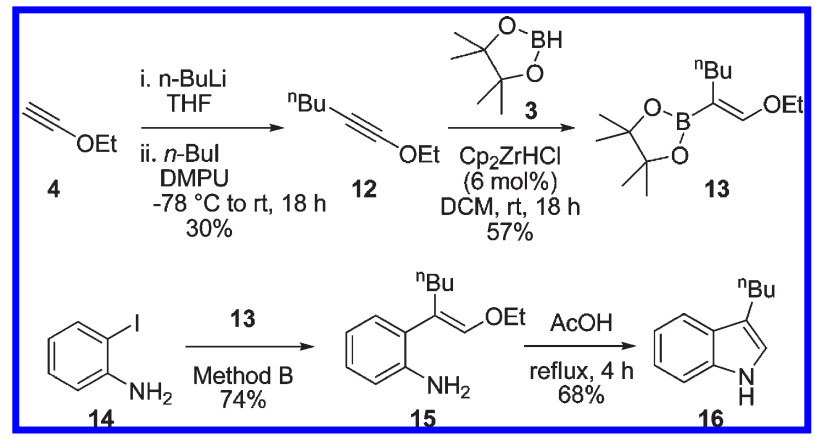

though functional, requires more reactive iodo-Pd-Ar intermediates to overcome its own steric hindrance-mediated lack of reactivity.

\section{Conclusion}

A two-step procedure has been established that yields an unprecedented range of aza- and diazaindole isomers from chloro- or bromoamino- $N$-heterocycles, including all pyridine regioisomers, without the need of protecting groups. The first step, a Suzuki-Miyaura coupling with an ethoxyvinylborolane, has been fully investigated to find the optimum conditions which involve using $3 \mathrm{~mol} \%$ of $\mathrm{SPhos} / \mathrm{Pd}(\mathrm{OAc})_{2}(2.5: 1)$ as catalyst in refluxing $\mathrm{MeCN} /$ $\mathrm{H}_{2} \mathrm{O}$ (3:2) with $\mathrm{K}_{3} \mathrm{PO}_{4}$ as base or, when more forcing conditions are required, in refluxing $\mathrm{MeCN}$ with $\mathrm{KOH}$ as base. The second step, acetic acid-catalyzed cyclization to form the azaindole, takes place readily to afford the azaindoles in high yields. As intended, this route does not introduce a substituent in the 2-position.

\section{Experimental Section}

(E)-2-(2-Ethoxyvinyl)-4,4,5,5-tetramethyl-1,3,2-dioxaborolane (5). Ethoxyethyne $(40 \% \mathrm{w} / \mathrm{w}$ solution in hexane, $6.25 \mathrm{~mL}$, $35.7 \mathrm{mmol})$ was dissolved in DCM $(60 \mathrm{~mL})$ under $\mathrm{N}_{2}$ and cooled to $0{ }^{\circ} \mathrm{C}$. To this was added 4,4,5,5-tetramethyl-1,3,2-dioxaborolane (5.69 mL, $39.2 \mathrm{mmol}$ ) followed by the catalyst bis(cyclopentadienyl)zirconium(IV) chloride hydride $(0.55 \mathrm{~g}, 2.1 \mathrm{mmol})$. The reaction mixture was warmed to rt and stirred overnight. It was then filtered through a pad of neutral alumina topped with a layer of Celite and eluted with DCM. Fractions containing product (TLC) were combined, evaporated, and dried in vacuo to give the title compound as a pale orange oil $(6.5 \mathrm{~g}, 92 \%): R_{f}=0.32$ (hexane $/ \mathrm{Et}_{2} \mathrm{O}$ 9:1); ${ }^{1} \mathrm{H}$ NMR (500 MHz, $\left.\mathrm{CDCl}_{3}\right) 7.03(1 \mathrm{H}, \mathrm{d}, J=14.5 \mathrm{~Hz}), 4.42$ $(1 \mathrm{H}, \mathrm{d}, J=14.5 \mathrm{~Hz}), 3.83(2 \mathrm{H}, \mathrm{q}, J=7.2 \mathrm{~Hz}), 1.28(3 \mathrm{H}, \mathrm{t}, J=7.2 \mathrm{~Hz})$, $1.25(12 \mathrm{H}, \mathrm{s}) ;{ }^{13} \mathrm{C}$ NMR (125 MHz, $\mathrm{CDCl}_{3}$ ) 163.0, 86.9 (very broad), 82.6, 64.3, 24.6, 14.4.

General Procedure for the Suzuki-Miyaura Coupling Reaction (Table 4). The appropriate starting aminoheterocycle (0.23-0.78 mmol), base (2 equiv, for type see Table 4$)$, and 2-(2-ethoxyvinyl)pinacolatoborolane (2 equiv) were added to a carousel tube and put under nitrogen using the vacuum/nitrogen line. The solvent (volume to make a $0.1 \mathrm{M}$ solution of substrate, for type see Table 4) was added, and the solution was briefly degassed by applying vacuum until boiling occurred and then flushed with nitrogen $(\times 3)$. Palladium(II) acetate $(3 \mathrm{~mol} \%)$ and SPhos $(7.5 \mathrm{~mol} \%)$ were added, and the mixture was further degassed as described above. This mixture was then heated at reflux overnight after which time the reaction was worked up by 
the addition of water $(8-27 \mathrm{~mL})$ and extraction with DCM $(3 \times$ 8-27 $\mathrm{mL}$ ). The combined organic layers were dried over $\mathrm{MgSO}_{4}$, filtered, concentrated, and purified as stated in the Supporting Information.

(E)-3-(2-Ethoxyvinyl)pyridin-4-amine (6). The crude material was purified by silica column chromatography $\left(1 \mathrm{M} \mathrm{NH}_{3}\right.$ in $\mathrm{MeOH}$ solution) in DCM $0-10 \%$ to give the title compound as a cream solid: $\mathrm{mp}=75-77{ }^{\circ} \mathrm{C} ; R_{f}=0.27\left(\mathrm{DCM} / 1 \mathrm{M} \mathrm{NH}_{3}\right.$ in MeOH solution 9:1); IR ( NaCl) $v$ 3482, 3405, 3054, 2985, 1656, $1641,1617 \mathrm{~cm}^{-1} ;{ }^{1} \mathrm{H}$ NMR $\left(500 \mathrm{MHz}, \mathrm{CDCl}_{3}\right) 8.15(1 \mathrm{H}, \mathrm{s}), 8.10$ $(1 \mathrm{H}, \mathrm{d}, J=5.5 \mathrm{~Hz}), 6.76(1 \mathrm{H}, \mathrm{d}, J=12.7 \mathrm{~Hz}), 6.51(1 \mathrm{H}, \mathrm{d}, J=5.5$ $\mathrm{Hz}), 5.62(1 \mathrm{H}, \mathrm{d}, J=12.7 \mathrm{~Hz}), 4.17(2 \mathrm{H}, \mathrm{br} \mathrm{s}), 3.93(2 \mathrm{H}, \mathrm{q}, J=7.0$ $\mathrm{Hz}), 1.36(3 \mathrm{H}, \mathrm{t}, J=7.0 \mathrm{~Hz}) ;{ }^{13} \mathrm{C} \mathrm{NMR}\left(125 \mathrm{MHz}, \mathrm{CDCl}_{3}\right) 150.1$, 149.9, 148.1, 147.9, 117.7, 109.3, 97.7, 66.4, 14.8; MS (ESI) $m / z$ $165\left([\mathrm{M}+\mathrm{H}]^{+}, 100\right)$; HRMS (ESI) found $[\mathrm{M}+\mathrm{H}]^{+}$165.1024, $\mathrm{C}_{9} \mathrm{H}_{12} \mathrm{~N}_{2} \mathrm{O}$ requires $[\mathrm{M}+\mathrm{H}]^{+} 165.1022$.

General Procedure for the Cyclization Reaction (Table 4). The appropriate starting ethoxyvinyl compound $\mathbf{1 0}$ was dissolved in acetic acid to make a $0.1 \mathrm{M}$ solution under $\mathrm{N}_{2}$. This was heated at reflux for $4 \mathrm{~h}$. The solvent was then evaporated and residual $\mathrm{AcOH}$ removed by azeotropic evaporation with toluene. The crude material was purified as stated below.

1H-Pyrrolo[3,2-c]pyridine (2) (Table 4, Entry 2). The crude material was purified by silica column chromatography $\mathrm{MeOH}$ in DCM $0-15 \%$ to give the title compound as a cream solid: $\mathrm{mp}=104-105{ }^{\circ} \mathrm{C}$ (lit. ${ }^{1} \mathrm{mp} 110-111^{\circ} \mathrm{C}$ ); $R_{f}=0.17(\mathrm{DCM} /$ MeOH 9:1); IR (NaCl) $v 3472,3018,1615,1578 \mathrm{~cm}^{-1} ;{ }^{1} \mathrm{H}$ NMR $\left(500 \mathrm{MHz} \mathrm{CDCl}_{3}\right) 9.86(1 \mathrm{H}$, br s), $8.98(1 \mathrm{H}, \mathrm{d}, J=0.8 \mathrm{~Hz})$, $8.30(1 \mathrm{H}, \mathrm{d}, J=5.8 \mathrm{~Hz}), 7.37(1 \mathrm{H}, \mathrm{d}, J=5.8 \mathrm{~Hz}), 7.32(1 \mathrm{H}, \mathrm{d}, J=$ $3.2 \mathrm{~Hz}), 6.68(1 \mathrm{H}, \mathrm{dd}, J=3.2,0.8 \mathrm{~Hz}) ;{ }^{13} \mathrm{C} \mathrm{NMR}(125 \mathrm{MHz}$, $\mathrm{CDCl}_{3}$ ) 143.1, 140.0, 139.9, 125.9, 125.0, 116.8, 112.8; MS (ESI) $m / z 119\left([\mathrm{M}+\mathrm{H}]{ }^{+}, 100\right)$; HRMS (ESI) found $[\mathrm{M}+\mathrm{H}]^{+}$ 119.0610, $\mathrm{C}_{7} \mathrm{H}_{6} \mathrm{~N}_{2}$ requires $[\mathrm{M}+\mathrm{H}]^{+} 119.0604 .{ }^{1} \mathrm{H}$ NMR data agrees with that given in the literature. ${ }^{16 \mathrm{a}}$

Acknowledgment. We acknowledge NHS funding to the NIHR Biomedical Research Centre and funding from Cancer Research UK program Grant No. C309/A8274. We also thank Dr. Amin Mirza, Mr. Meirion Richards, and Dr. Maggie Liu for their help with LC, NMR, and mass spectrometry.

Supporting Information Available: General experimental conditions, procedures for the optimization reactions, all compound characterization data not included in the main text, and copies of the NMR spectra of all compounds. This material is available free of charge via the Internet at http://pubs.acs.org. 